\title{
Catalytic gasification of dry and wet biomass
}

\author{
G. van Rossum *, B. Potic, S.R.A. Kersten, W.P.M. van Swaaij \\ University of Twente, Faculty of science and technology, Research institute Impact, P.O. Box 217, 7500 AE Enschede, The Netherlands
}

\section{A R T I C L E I N F O}

\section{Article history:}

Available online 2 July 2008

\section{Keywords:}

Biomass

Gasification

Catalysis

Reaction engineering

Syngas

\begin{abstract}
A B S T R A C T
Catalytic gasification of dry biomass and of wet biomass streams in hot compressed water are reviewed and discussed as potential technologies for the production of synthesis gas, hydrogen- and methane-rich gas. Next to literature data also new experimental results from our laboratory on catalytic gasification of pyrolysis oil and catalytic gasification of model components in hot compressed water are presented. The paper focuses on the present status of catalytic gasification of biomass, similarities and differences between dry and wet processes, and the challenges for future research and development from both catalysis and process point of view.
\end{abstract}

(C) 2008 Published by Elsevier B.V.

\section{Introduction}

Biomass is a sustainable candidate for the replacement of fossil sources, especially when it comes to the production of gaseous and liquid fuels for stationary and non-stationary applications (e.g. gasoline, diesel, kerosene, oxygenates, heavy fuel oil, SNG, $\mathrm{H}_{2}$ ). These fuels are essential for our present society and it is of paramount importance for the world's economy and stability that fuel supply is guaranteed in the future. It is envisaged that catalysis will play an important role in the production of bio-fuels, just as catalysis plays a major role in the conversion from fossil feeds to fuels currently. This paper deals with the catalytic production of synthesis gas, hydrogen- and methane-rich gas (Synthetic Natural Gas) from dry and wet ( $>70 \mathrm{wt} \%$ moisture) lignocellulosic biomass. Synthesis gas can be used as feedstock for many second generation bio-fuels, such as methanol, dimethylether, and Fischer-Tropsch diesel [1]. Future demands for hydrogen will rise in existing industries and/or because of the use in new technologies like fuel cells [2]. To cover the projected increase in demand it is necessary to improve hydrogen recovery in refineries and to utilize other potential sources like biomass [3]. Natural gas represents a large part of the European energy consumption and its sustainable substitute broadens the future fuel mix.

Catalytic gasification of dry biomass and of wet biomass streams in hot compressed water are reviewed and discussed in this paper as potential technologies for the production of the before mentioned gases. In addition to literature data also some new experimental results from our laboratory on catalytic

\footnotetext{
* Corresponding author. Tel.: +31 534893902; fax: +31534894738

E-mail address: g.vanrossum@utwente.nl (G. van Rossum).
}

gasification of pyrolysis oil and catalytic gasification of glucose and glycerol in hot compressed water are presented. This paper focuses on the problems encountered currently, similarities and differences between dry and wet processes, and the challenges for future research and development from both catalysis and process point of view.

\section{Experimental}

Gasification of pyrolysis oil was investigated in a continuous mini plant which consisted out of a bubbling fluidized bed (superficial gas velocities $\sim 10-30 \mathrm{~cm} / \mathrm{s}$ ) above which a fixed bed could be installed. The mini plant is described in detail (materials, experimental and set-up) by van Rossum et al. [4]. Gasification in hot compressed water was investigated in micro batch capillary reactors and in a micro continuous flow reactor. Potic et al. [5] and Knežević et al. [6] introduced and described the capillary batch reactors. The micro continuous flow reactor is a new development of our group [7] and is described in this paper in detail. Fig. 1 shows schematic representations of the continuous set-ups.

\subsection{Micro continuous flow reactor}

The continuous micro flow reactor for gasification in hot compressed water has been developed to allow simple, safe and cheap experimentation without using a special high-pressure infrastructure. Such a system should be flexible with easy to replace parts allowing fast cleaning and short experimental runs at steady state. These demands were met by miniaturization and by elimination of a complex multi-phase pressure reduction valve.

The continuous supercritical water gasification (SCWG) reactor system consisted of a high-pressure liquid chromatography (HPLC) 
(A)

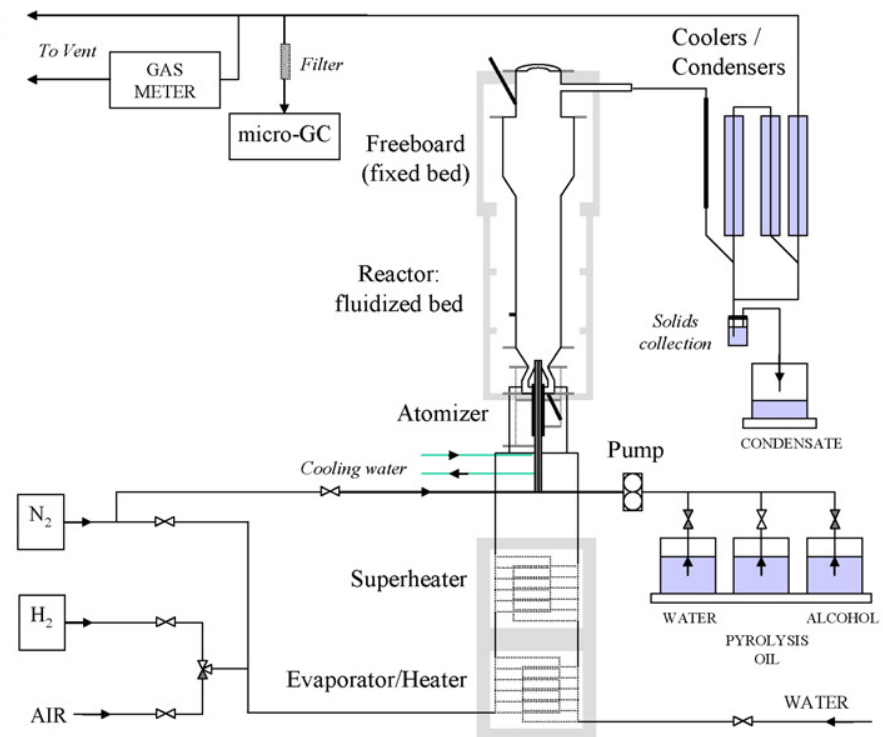

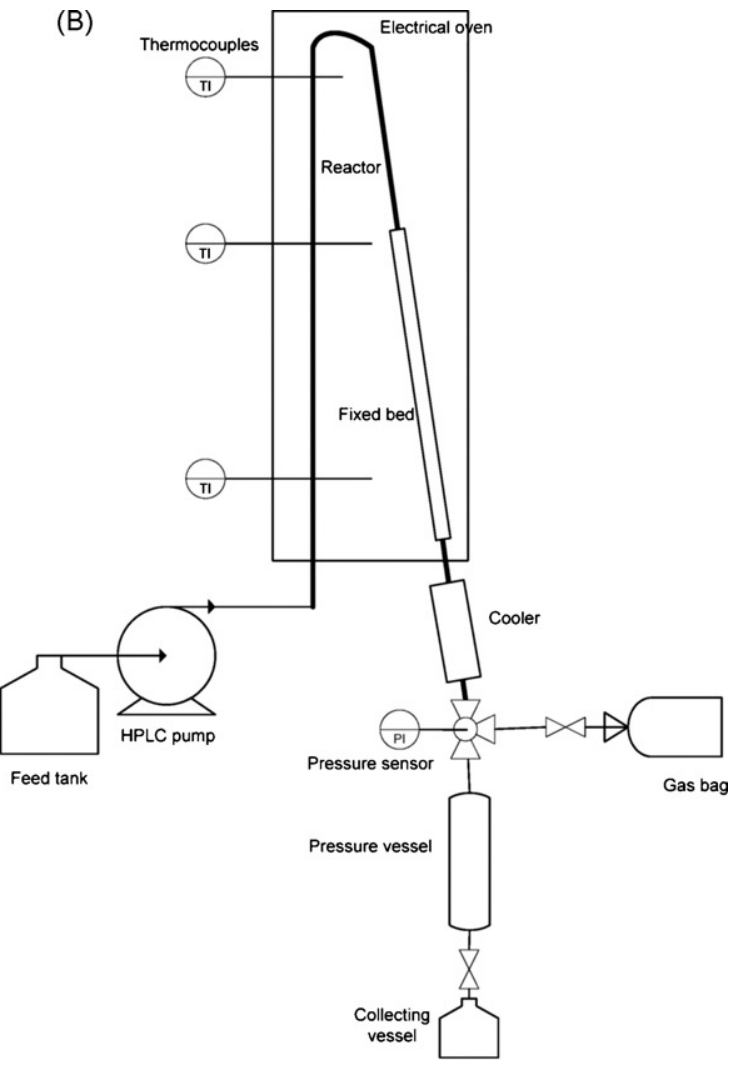

Fig. 1. Experimental set-ups for gasification of pyrolysis oil (A) and gasification in hot compressed water using a continuous capillary reactor (B).

piston pump, a tubular reactor, an electrical oven, a cooler, a pressure vessel, a liquid collection vessel and a sampling bag for gasses. Fig. 1(B) is a schematic representation of the experimental set-up. Stainless steel 316 and Inconel capillaries with an internal diameter of $1 \mathrm{~mm}$ and a length of $1 \mathrm{~m}$ were used as tubular reactors $(V=0.785 \mathrm{ml})$. Quartz reactors were also tested but these were found to be too fragile for continuous operation. The set-up could in principle be operated with a catalytically inert reactor like quartz but this could not yet be technically solved.

The flow rate of the feedstock was controlled accurately with the HPLC pump. This pump could deliver flow rates of water in the range of $0.01-24 \mathrm{~N} \mathrm{ml} / \mathrm{min}$ against a maximum pressure of 500 bar. The pressure directly after the pump was measured and monitored with the in-built pressure sensor of the pump. For the rapid cooling of the reactor effluent a cooler was placed just after the oven. The cold liquid, gasses and entrained solids (if any) were collected in a high-pressure vessel $(V=30 \mathrm{ml})$, which was connected to a pressure sensor. Between the cooler and the pressure vessel a simple valve was placed. This pressure vessel was also used to start-up the system in the following way. While the valve was closed, the vessel was pressurized with helium and water which was pumped into the reactor and cooler until the pressures up and downstream of the valve equalized. Then the valve was opened and the helium in the vessel maintained the pressure in the system. Hereafter, the experiment was started by switching from water to the feedstock solution. During a typical experiment the pressure increased ca. 50 bar. The representative pressure of an experiment was defined as the average of the start and end pressure of that test. We allowed for this pressure increase, because in the batch capillaries it was observed that the operating pressure did not affect the results in the range of 40400 bar [10]. During operation, the temperature was measured with three thermocouples (tip $=0.5 \mathrm{~mm}$ ) placed on the outer wall of the capillary. The temperature difference between these thermocouples never exceeded more than $3{ }^{\circ} \mathrm{C}$ during operation. Additionally, the axial temperature profile inside the reactor was initially measured by a movable thermocouple. By these measurements it was shown that the first $11 \mathrm{~cm}$ of the reactor (total length is $1 \mathrm{~m}$ ) were needed to reach the final reactor temperature for a typical flow rate of $0.04 \mathrm{~N} \mathrm{ml} / \mathrm{min}$. For all employed flow rates the length of the heating zone was determined. For the catalytic tests, the last $30 \mathrm{~cm}$ of the capillary was filled with catalyst. The catalyst zone was placed between two supports to ensure fixed bed operation. The residence time in the catalytic bed was ca. $10 \mathrm{~s}$. After the experiments, the gas products were collected in a sampling bag, which was then connected to a GC for the gas analysis. On basis of the readings of the GC, the total number of moles present in the pressure vessel (calculated from the known $T$, $p$ and $V$ of this vessel), and the amount of feedstock, the mass balance (gas production and conversion) was calculated.

\subsection{Materials}

For examining gasification in hot compressed water, besides pine wood, mostly model compounds (glucose and glycerin) were used. A ruthenium catalyst ( $3 \mathrm{wt} \% \mathrm{Ru}$ on rutile $\mathrm{TiO}_{2}, d_{\mathrm{p}} \sim 70-$ $100 \mu \mathrm{m}$ ) was used which was supplied by Pacific Northwest National Laboratory. This catalyst was selected for its proven high activity at $350{ }^{\circ} \mathrm{C}$ [8]. Recently, cheaper Ni-based catalysts have been proposed for this purpose [9].

For the dry gasification, fast pyrolysis oil of both beech and pine wood was used which were produced in the pilot plant facility $(200 \mathrm{~kg} / \mathrm{h})$ of the company BTG. Two different kind of commercial steam reforming catalysts, both supplied by Johnson Matthey were used: KATALCO 23-4Q (K23, methane) and KATALCO 46-3Q (K46, naphtha, see also ref. [4]). 
The elemental analysis and water content of the used wood and pyrolysis oils are given in Table 1 .

\subsection{Extent of gasification and gas yield calculations}

In the results presented, the extent of gasification $\left(Y_{c}\right)$ is defined as the carbon to gas conversion. $Y_{\mathrm{c}}$ is the fraction of carbon from the feed converted to the following gaseous products: $\mathrm{CH}_{4}, \mathrm{CO}, \mathrm{CO}_{2}$, $\mathrm{C}_{2} \mathrm{H}_{4}, \mathrm{C}_{2} \mathrm{H}_{6}, \mathrm{C}_{3} \mathrm{H}_{6}$ and $\mathrm{C}_{3} \mathrm{H}_{8}$. The gas productions are defined as normal cubic meter $\left(\mathrm{N} \mathrm{m}^{3}, 0{ }^{\circ} \mathrm{C}\right.$ and $\left.1 \mathrm{~atm}\right)$ per kilogram of dry feed. The hydrogen yield is defined as the fraction of maximum amount of hydrogen, which can be produced according to the following reaction:

$\mathrm{C}_{x} \mathrm{H}_{y} \mathrm{O}_{z}+(2 x-z) \mathrm{H}_{2} \mathrm{O} \rightarrow x \mathrm{CO}_{2}+\left(y \frac{1}{2}+2 x-z\right) \mathrm{H}_{2}$

In the pyrolysis oil gasification experiments, the carbon to gas conversion, gas production and hydrogen yield (if possible) are calculated from steady-state operation, excluding start-up of the catalysts.

The equivalence ratio $(\lambda)$ is defined as the fraction of oxygen added for total combustion of the feedstock according to:

$\mathrm{C}_{x} \mathrm{H}_{y} \mathrm{O}_{z}+\left(x+y \frac{1}{4}-z \frac{1}{2}\right) \mathrm{O}_{2} \rightarrow x \mathrm{CO}_{2}+y_{\frac{1}{2}} \mathrm{H}_{2} \mathrm{O}$

The steam over carbon ratio $(\mathrm{S} / \mathrm{C})$ is defined as the ratio of total amount of moles of steam, including the water content of the feedstock, over moles of carbon in the feedstock.

\subsection{Equilibrium calculations}

Equilibrium calculations were performed according to the Gibbs free energy minimization method [11]. Fugacity coefficients were calculated with the Modified Soave Redlich Kwong equation of state [12]. The parameters for the Modified Soave Redlich Kwong equation of state were obtained from Bertucco et al. [13], Soave [14] and NIST-JANAF [15].

\section{Gasification of dry biomass and biomass pyrolysis oil}

\subsection{Literature}

For complete reviews on gasification of dry biomass including reactor types, problems encountered, and application of catalysts the reader is referred to refs. [17-20].

The developments in the coal and oil industry have led to three archetype gasifiers, viz.: fixed bed, fluid bed and entrained flow. From extensions of these archetypes and combinations of them several derived systems were developed such as slagging fixed beds, circulating fluid beds, high temperature fluid beds, twin reactors with separate zones for reduction and oxidation, etc. Gasifiers operated below $950{ }^{\circ} \mathrm{C}$ (low temperature gasifiers) generate a raw synthesis gas / fuel gas $\left(\mathrm{CO}, \mathrm{H}_{2}, \mathrm{CO}_{2}, \mathrm{H}_{2} \mathrm{O}, \mathrm{C}_{x} \mathrm{H}_{y} \mathrm{O}_{z}\right.$, tar, and in case of air blown gasification $\mathrm{N}_{2}$ ) that needs extensive

Table 1

Elemental analyses and water content determinations of the biomass and pyrolysis oils used

\begin{tabular}{llcc}
\hline & Pine wood & Beech wood pyrolysis oil & Pine wood pyrolysis oil \\
\hline $\mathrm{C}$ & 49.9 & $30.4-37.7$ & $38.1-39.9$ \\
$\mathrm{H}$ & 6.0 & $7.6-7.9$ & $7.9-8.3$ \\
$\mathrm{O}$ & 44.1 & $54.4-61.7$ & $51.6-53.7$ \\
$\mathrm{~N}$ & 0.1 & $<0.01-0.27$ & $0.13-0.16$ \\
$\mathrm{~S}$ & nd & $<0.01$ & $<0.01$ \\
$\mathrm{H}_{2} \mathrm{O}$ & 7.5 & $32.5-43.7$ & $29.7-30.4$ \\
\hline
\end{tabular}

All values are in wt\%. The oxygen content is calculated by difference. nd: not detected. cleaning and conditioning before it can be used as feed for the production of fuels and chemicals. Operation above $1300{ }^{\circ} \mathrm{C}$ (high temperature gasifiers) results in relatively clean synthesis gas $\left(\mathrm{CO}, \mathrm{H}_{2}, \mathrm{CO}_{2}, \mathrm{H}_{2} \mathrm{O}\right)$. Intermediate gasification temperatures $\left(950{ }^{\circ} \mathrm{C}<T<1300^{\circ} \mathrm{C}\right.$ ) are unfavorable because the ash becomes partly molten/partly solid, a situation that is almost impossible to handle in a reactor.

In the 1970s, against the background of a foreseen natural gas shortage, research into catalytic gasification of coal for the production of synthetic natural gas (SNG) was started. The Exxon CCG (Catalytic Coal Gasification) process reached the demonstration phase but did not become commercial due to the discovery of new gas fields [16].

For synthesis gas production dry biomass can be converted by means of entrained flow gasifiers [17,21], similar to coal and oil gasifiers. These entrained flow biomass gasifiers are expected to be operated at a temperature above $1300{ }^{\circ} \mathrm{C}$ and require pure oxygen as oxidant. As a result the scale of operation will be $100 \mathrm{MW}$ or above.

In order to produce a clean tar and methane free syngas at moderate process temperatures $\left(<950{ }^{\circ} \mathrm{C}\right)$, various groups have studied the application of catalysts to biomass gasification. Lowering the temperature of the gasifier reduces equipment costs and allows for gasification at smaller scale.

The catalysts are either pre-mixed with the biomass, used (partly or fully) as bed material in fluid bed gasifiers or applied downstream of the gasifier for product gas upgrading.

Cheap disposable catalysts have been used to create an upgraded fuel gas rather than to produce actual syngas. Dolomite $[18,22-24]$ has gained the most attention as it is very cheap and easy to apply. It is applied inside the gasifier to promote direct tar cracking or separately in a bed downstream of the gasifier. Although its calcined form can almost fully convert tars it is more often used as a tar-reducer, a guard material, allowing the usage of more active but also more sensitive catalysts downstream [25]. However, dolomite is not able to effectively convert methane and suffers from attrition. [24,26]. Olivine [26,27] is much more resistant to attrition than dolomite with a somewhat lower activity for tar destruction. Impregnation of the olivine with nickel is possible to enhance its activity while maintaining its strength [28]. Alkali metals are most effective when impregnated onto the biomass giving a tar free gas, especially when potassium carbonate is being used. Catalyst deactivation, catalyst make-up and fluidization problems still need a lot of research attention before these catalysts could be effectively applied [18].

When besides tars also complete methane conversion is desired, high steam (and dry) reforming activity of the catalyst is of vital importance. Nickel on alumina-based catalysts have been used in the industry for naphtha and natural gas reforming for many years and it was therefore also logical to test them for biomass gasification applications. Caballero et al. [25] and Simell et al. [29] have been able to effectively eliminate the tars in the biomass derived gas together while realizing a significant decrease of methane using crushed and/or as-received commercial catalyst or dedicated monolith beds. For complete tar and methane elimination, only downstream secondary reactors after the gasifier have been successful.

Czernik et al. [30,31] initiated research on gasifying/reforming a biomass derived energy carrier, namely fast pyrolysis oil (also called bio-oil). While Czernik started research on model compounds and the water soluble fraction of pyrolysis oil, van Rossum et al. [32] started to gasify the whole pyrolysis oil for syngas production. Major advantages of converting pyrolysis oil rather than biomass are that a liquid is created which is easier to handle, store and transport, the volumetric energy density is much higher, and minerals are separated from the organic compounds. 


\subsection{Experimental results of pyrolysis oil gasification}

Catalytic biomass or pyrolysis oil conversion in a fluidized bed suffers from irreversible activity loss of the catalyst [4,33]. In Fig. 2 an example is given of pyrolysis oil gasification in a single fluidized bed using a fresh commercial catalyst. After an initial high activity, the hydrogen production decreases while methane production increases. These phenomena level off to an equilibrium activity which the catalyst can then maintain. The activity loss has been ascribed mainly to attrition and sintering of the catalyst [4].

While research is being done on creating a strong attritionresistant catalyst for direct fluid bed biomass and pyrolysis oil conversion [34,28], separating different process steps might also be beneficial:

- Existing commercial catalysts can be used without modifications.

- Biomass pyrolysis or pyrolysis oil re-evaporation can be done at lower temperatures which has benefits for the overall energetic efficiency and allows options for process integration.

- Carbonaceous particles and deposits formed can be separated from the gas before it comes into contact with catalysts which can be used for heat generation.

van Rossum et al. [4] proposed and tested a staged reactor consisting of an inert fluidized bed of sand particles in which the pyrolysis oil is atomized followed by a fixed catalytic bed for the gasification/ reforming of vapors and gases. Fig. 3 shows gas production in time for this staged system where both beds were kept at around $800^{\circ} \mathrm{C}$.

No methane production was found after 6 consecutive experiments (including burn-off reactivation cycles) using the same catalyst which lasted $10 \mathrm{~h}$ of actual gasification time and in a single long duration run $(11 \mathrm{~h})$. The catalyst is used as received. It was designed for commercial use, which is pressurized steam reforming. No crushing of the catalysts was applied. Under these conditions the amount of catalyst which actually participates in the reaction is very low due to mass transfer limitations [35].

Fig. 4 shows the syngas, methane and $C_{2}-C_{3}$ gas production of two ( $B$ and $D$ ) experiments done in the staged reactor set-up where the fixed bed temperatures is kept constant $\left(682 \pm 5^{\circ} \mathrm{C}\right)$ while the fluidized bed temperatures are varied. Fig. 4(A and C) shows the noncatalytic production using only a fluidized bed at that temperature for comparison.

The fixed bed temperature has been set at such a moderate temperature $\left(682 \pm 5{ }^{\circ} \mathrm{C}\right)$ that the activity of the catalyst is low,

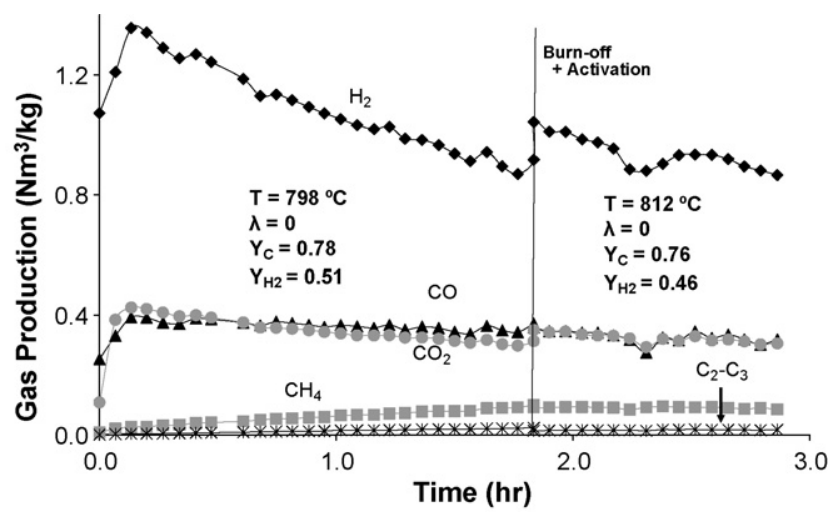

Fig. 2. Gas production of fluidized catalytic (K46; crushed) pyrolysis oil gasification versus time. Two consecutive runs where burn-off and hydrogen reactivation took place were conducted between the experiments: pyrolysis oil flow $=0.60,0.49 \mathrm{~kg} / \mathrm{h}$ (beech, wet basis), $\mathrm{S} / \mathrm{C}$ ratio $=2.8,3.2$ respectively; catalyst (K46) fluidized bed hold-up $=0.32 \mathrm{~kg}, d_{\mathrm{p}} \sim 200-300 \mu \mathrm{m}$; sand hold-up $=4.5 \mathrm{~kg}, d_{\mathrm{p}} \sim 150-450 \mu \mathrm{m}$.

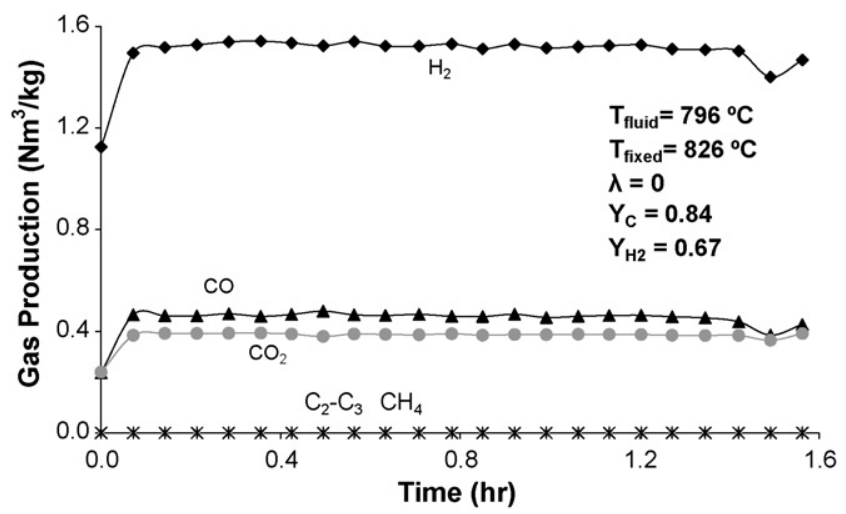

Fig. 3. Gas production of the staged pyrolysis oil gasifier. Pyrolysis oil flow $=0.51 \mathrm{~kg} /$ $\mathrm{h}$ (pine derived, wet basis); $\mathrm{S} / \mathrm{C}$ ratio $=2.3$; sand fluidized bed hold-up $=5.0 \mathrm{~kg}$, $d_{\mathrm{p}} \sim 150-450 \mu \mathrm{m}$; catalyst $(\mathrm{K} 46+\mathrm{K} 23$; as received) fixed bed hold-up $=5.5+$ $2.5 \mathrm{~kg}$ respectively.

especially for methane reforming. The methane and $C_{2}-C_{3}$ gas production is lowest when the fluidized bed is kept at a lower temperature (Fig. 4(C and D)) followed by a catalytic bed. When the fluidized bed is at a lower temperature, thermal cracking reactions are low which reduces the production of methane, $C_{2}-C_{3}$ and secondary and tertiary tars. The vapor/gas mixture then contains a lot of oxygenated tars (primary tar) which are more reactive towards reforming than a thermally cracked vapor/gas mixture including hydrocarbons and secondary and tertiary tars. If the temperature of the fluidized bed would be even lower, it will function more as an evaporator. Some carbonaceous deposits are inevitably formed due to the nature of the pyrolysis oil, but these may be required for heat generation in the integrated process. By applying a temperature gradient over the catalytic bed, the whole reaction path of producing methane and secondary and tertiary tars might be avoided altogether which paves the way to low temperature clean syngas production via direct reforming of pyrolysis vapors. Dedicated catalysts for reforming oxygenated compounds are investigated in refs. [36-38].

\section{Gasification in hot compressed water}

\subsection{Literature}

The high moisture content of so-called wet biomass streams makes conventional thermo-chemical technologies inefficient due to the high-energy requirement for water evaporation $(2.4 \mathrm{MJ} / \mathrm{kg}$

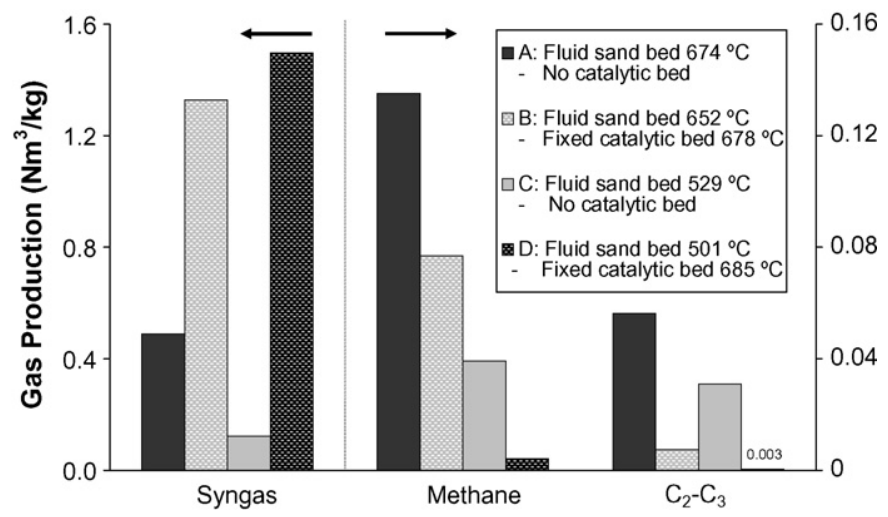

Fig. 4. Overview of syngas, methane and $C_{2}-C_{3}$ gas production of inert fluidized bed gasification versus the staged reactor at similar temperatures of the fluidized bed. Pyrolysis oil flow $=\sim 0.5-1.6 \mathrm{~kg} / \mathrm{h}$ (beech and pine, wet basis); $\mathrm{S} / \mathrm{C}$ ratio $=1.0,2.4$, $1.1,2.5$; sand fluidized bed hold-up $=4.5,5.0,4.0,5.1 \mathrm{~kg}, d_{\mathrm{p}} \sim 150-450 \mu \mathrm{m}$; catalyst (K46) fixed bed hold-up $=0,4.7,0,5.0 \mathrm{~kg}$ respectively. 
at atmospheric conditions). Although wet biomass (moisture $>70 \mathrm{wt} . \%$ ) has a very low overall heating value, products with a high heating value can still be extracted from it by applying advanced conversion processes. Biomass gasification in hot compressed water $\left(T=250-700{ }^{\circ} \mathrm{C}, P>200 \mathrm{bar}\right)$ is considered as a promising technique to convert such wet streams to a gas that is rich in either hydrogen or methane depending on the operating conditions and applied catalysis. Promises of biomass gasification in supercritical water are that [39]:

- The technology is suitable for efficient processing of wet feedstock ( $>70$ wt.\% moisture); evaporation of water is avoided and feedstock/product heat exchange is quite well possible.

- Contrary to anaerobic digestion and fermentation processes, the technology allows in principle for complete feedstock conversion and sterilization.

- The product gas is made available at high pressure ( $>200$ bar) and, for its application, expensive gas compression can be avoided.

- The product gas is clean; minerals, metals, and the undesired gases like $\mathrm{CO}_{2}, \mathrm{H}_{2} \mathrm{~S}$ and $\mathrm{NH}_{3}$ (which have a high solubility in compressed water) remain in the water phase and can thus be recovered.

- The product gas is not diluted with inert gas.

- The selectivity towards either methane or hydrogen can be controlled with temperature, pressure and the application of catalysts.

- Sequestration of (pure) $\mathrm{CO}_{2}$ seems convenient (negative $\mathrm{CO}_{2}$ balance).

These promises however go together with a series of problems that need to be solved in the process development. Pumping of biomass slurries to pressures of up to 300 bar is a challenge. The high temperatures and pressures involved put serious demands on the construction materials to be used, especially because corrosion problems are expected. Heat exchange between the reactor feed and effluent is required to make the process efficient, but heating of a biomass slurry is likely to cause fouling and plugging as the biomass starts to decompose already around $250{ }^{\circ} \mathrm{C}$. Catalysts need to operate under severe and fouling conditions. Ash deposits will cause problems, and an effective ash removal system must therefore be part of the reactor/process. At the time of writing several pilot plants are in operation [39,7] to facilitate the process development.

\subsection{Non-catalytic gasification in hot compressed water}

The study of non-catalytic gasification of biomass in hot compressed water is not straightforward. Nearly all work was done in small metal (stainless steel, inconel, hastelloy) reactors [40-42] for which it was shown that their walls have significant, but undefined, catalytic activity $[42,10]$. We have performed gasification experiments in catalytically inert quartz capillaries [10,43]. At sub critical temperatures the pressure inside the capillaries was always slightly higher than the water vapor pressure at the corresponding temperature; above the critical point the pressure was always above 250 bar. The reaction time (unless stated otherwise) was $600 \mathrm{~s}$ (including $120 \mathrm{~s}$ heating) at sub critical conditions) and $60 \mathrm{~s}$ (including 5-10 s heating) at super critical conditions. The results shown in Fig. 5 are obtained in these capillaries reactors. The following observations can be made:

- At sub critical conditions $\left(T<374{ }^{\circ} \mathrm{C}\right)$ there is only limited gas formation $\left(Y_{\mathrm{c}}<0.10\right)$ (see Fig. $5 \mathrm{~A}$ and $\mathrm{C}$ ). Oil and char are the main products in this regime.
- Between 400 and $650{ }^{\circ} \mathrm{C}$ the extent of gasification is a strong function of the temperature (Fig. 5A).

- The extent of gasification reaches a constant level beyond $650{ }^{\circ} \mathrm{C}$ (Fig. 5A).

- This maximum in gas formation depends on the concentration of organics in the feed solution: lower concentrations result in a higher $Y_{\mathrm{c}}$ (Fig. 5A). Despite the high temperature, only for very diluted feeds ( $<5$ wt.\%) can complete gasification be achieved. In case of incomplete gasification, full conversion of the feedstock is realized, but next to gas also oil and char are formed.

- A slurry of lignocelluloses particles (pine wood) has a considerable lower maximum extent of gasification than a solution of a sugar (glucose) under identical conditions (Fig. 5A). This clearly shows the limits of using model components to develop processes for real wet biomass streams like manure, spent grain liquor, cheese way, sludge, etc.

- At sub critical temperature $\mathrm{CO}_{2}(>75 \mathrm{vol} . \%$ ) is the abundant gaseous product. Between 500 and $700{ }^{\circ} \mathrm{C}$ a mixed gas is produced with a high content of $\mathrm{CO}$. At high temperature $\left(800^{\circ} \mathrm{C}\right)$ the gas becomes richer in hydrogen and lowering the feedstock concentration results in less $\mathrm{CO}$. Methane and $\mathrm{C}_{2}-\mathrm{C}_{3}$ are always present in significant concentrations (Fig. 5B). All non-catalytic gasification gas compositions are far from chemical equilibrium.

- The rates of the gasification reactions show strong temperature dependence: at $600{ }^{\circ} \mathrm{C}$ ca. $40 \mathrm{~s}$ reaction time is required to reach the maximum gasification level while at $350{ }^{\circ} \mathrm{C}$ ca. $250 \mathrm{~s}$ are needed (Fig. 5C).

Based on the works of Kruse and co-workers [44,45], Cortright et al. [46], Bobleter et al. [47], Minowa et al. [48], Kaybelaml et al. [49] and Waldner et al. [9] a simplified lumped reaction path scheme for the conversion of small carbohydrates $\left(\leq \mathrm{C}_{6}\right)$ in hot compressed water can be deduced. This simplified scheme, presented in Fig. 6, already consist of many serial and parallel reactions towards gasses. Next to routes to form gasses, there are also several paths identified to undesired byproducts, viz. oil, char (coke). The scheme is used in this work to discuss the actions of catalysts.

\subsection{Catalytic gasification in hot compressed water}

Pacific Northwest National Laboratory (US) developed a catalytic process for the destruction of organic waste at ca. $350{ }^{\circ} \mathrm{C}$ while producing a methane rich gas [50,51,8,52]. In an extensive research program that started in the eighties of the last century tests were carried out at laboratory and pilot scale focusing on both catalyst and process development. Ruthenium on rutile titania, ruthenium on carbon and stabilized nickel catalysts showed the highest activity and the best stability. With these catalyst nearly $100 \%$ gasification of model components (1-10 wt\% in water) was achieved, while without catalyst the extent of gasification is very limited at this temperature (see Fig. 5C). The gas produced consisted of nearly only $\mathrm{CH}_{4}$ and $\mathrm{CO}_{2}$, as dictated by the overall thermodynamic equilibrium. The catalytic process was carried out in a series of fixed bed reactors. When using feedstock materials with the tendency to produce char/coke, a continuous stirred-tank reactor (CSTR) was required before the fixed bed to soften the feed and to prevent the buildup of solids. Pilot plant runs using complex feeds like potato waste and manure were carried out. On model components, the pilot plant was running for up to 33 weeks without operational problems or serious catalyst deactivation. The required liquid hourly space velocity (LHSV) was in the range of $1.5-3.5 \mathrm{~N} \mathrm{~m}_{\text {feed }}^{3} / \mathrm{m}_{\text {cat }}^{3} / \mathrm{h}$. For a waste disposal process these LHSVs are acceptable, but for the production of gaseous energy carriers from biomass the activity is too low. For a small plant of 

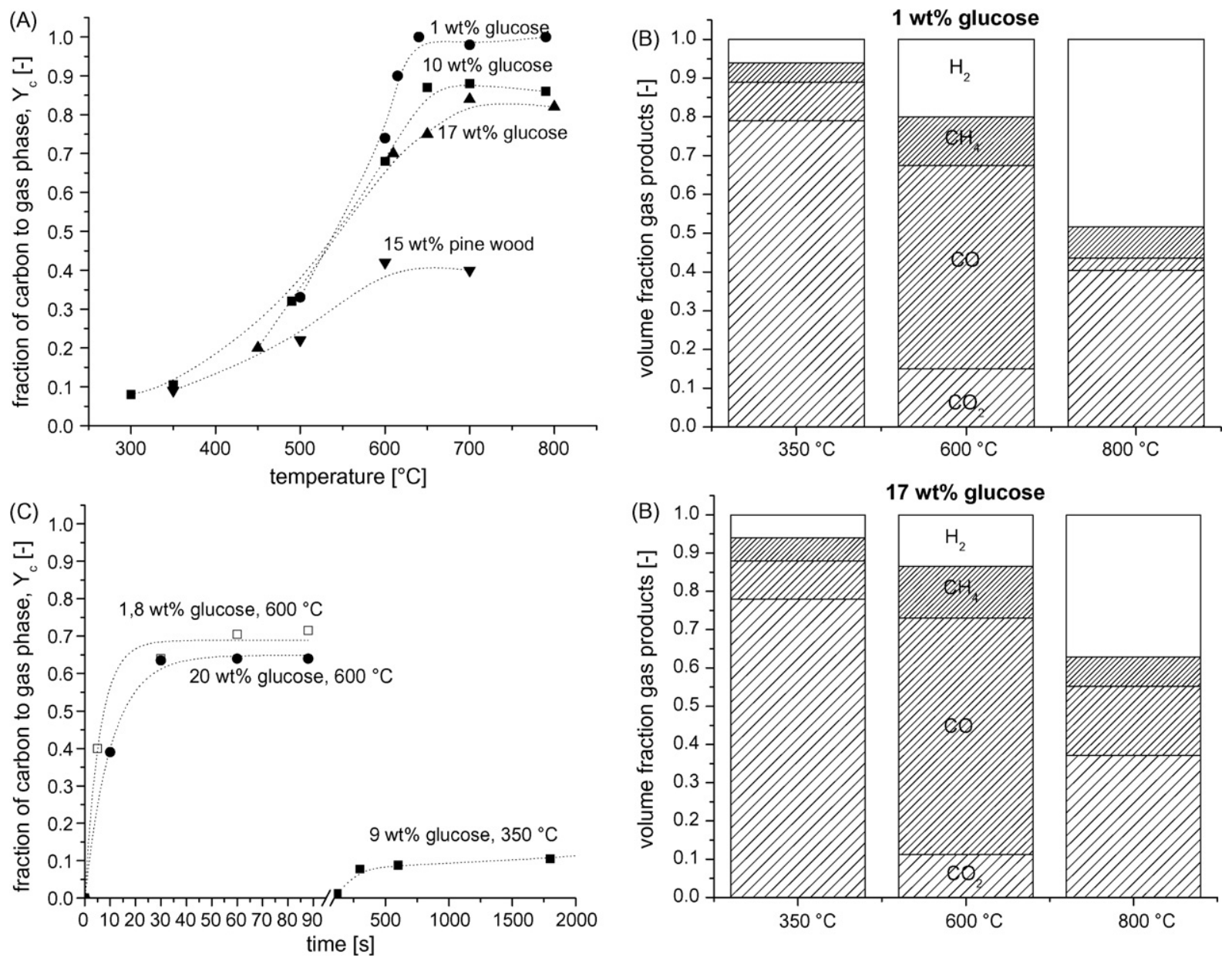

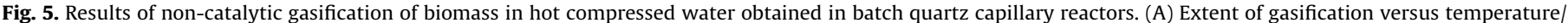
concentration/feed, (B) gas composition (normalized) versus temperature/concentration, (C) extent of gasification versus reaction time/temperature/concentration.

$100 \mathrm{MW}$ taking in a feed that contains $10 \mathrm{wt} \%$ organics already $40,000 \mathrm{~m}^{3}$ of catalytic bed would be required (for LHSV $=2.5 \mathrm{~h}^{-1}$ ). Recently, Vogel and co-workers [9] reported high extents of gasification and equilibrium methane yield of concentrated (up to $30 \mathrm{wt} \%$ ) wood sawdust slurries using Raney nickel as catalyst at $400{ }^{\circ} \mathrm{C}$. For complete gasification, $90 \mathrm{~min}$ reaction time was required in their batch reactor. How these catalysts enhance the extent of gasification at these low temperatures has not been completely clarified. Either they accelerate the rate of the

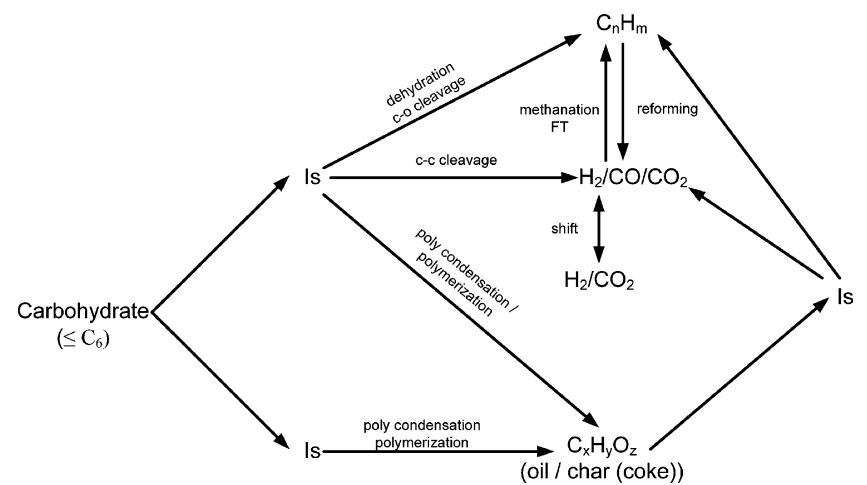

Fig. 6. Simplified reaction path scheme for the gasification of small carbohydrates in hot compressed water. All paths can be catalytic or non-catalytic. Is: intermediate components. gasification reaction relative to the rate of poly condensation/ polymerization reactions, or they are able to gasify the formed polymers, or a combination of both (see Fig. 6). However, after comparing reaction rates it can be argued that the majority of the gas is produced via gasification of partially polymerized components: in non-catalytic experiments with monomer sugars as feed maximal oil (polymerized components) yields are obtained for reaction times of 2-5 min [53], whereas in catalytic test 30 up to 90 min reaction time [52,9] are needed to achieve complete gasification. Obviously, these catalysts catalyze all gas phase component reactions because good agreement was found between the observed gas composition and the gas composition dictated by thermodynamic equilibrium. Reported problems with respect to the catalysts are poisoning through trace components such as sulfur, magnesium, calcium and the growth of the active metal crystals during operation (sintering). A general problem of the near and super critical region is that it enhances leaching of the catalytic active phases and degeneration of the support. Hot compressed water is a good solvent for most organic chemicals which is especially useful to keep coke precursors dissolved. If coke is formed on the surface of the catalysts, the high $\mathrm{H}_{2} \mathrm{O}$ concentration helps in keeping it clean via gasification. In accordance with that it was found that coke formation on the catalyst surface is a minor problem [8].

Huber et al. [54] and Cortright et al. [46] reported interesting catalysis around $230^{\circ} \mathrm{C}$ for the production of hydrogen rich gas from small oxygenated hydrocarbons. They were able to decrease 
the methane formation rate via $\mathrm{C}-\mathrm{O}$ bond cleavage and methanization (hydrogenation) while maintaining the high rates of $\mathrm{C}-\mathrm{C}$ bond cleavage and shift for hydrogen production (see Fig. 6). Cortright used a Pt catalyst, Huber a Raney nickel catalyst promoted with tin. High hydrogen yields were obtained for methanol, ethylene glycol and glycerol. However, with sorbitol and glucose as feedstock already significant amount of methane were being produced next to hydrogen. Though in an embryonic stage, the methodology of decelerating methane producing reactions at catalytic sites while keeping a high rate of catalytic hydrogen production seems promising to produce hydrogen rich gas at conditions for which overall chemical equilibrium dictates methane rich gas, viz. at sub critical temperature and at the combination of high temperature and high concentration of organics. In this concept, it will be important to decrease homogeneous reactions to undesired by-products (oil/char $/ \mathrm{CH}_{4}$ ) and to increase the reaction rate. This is quite a challenge for both catalyst and reactor design.

For high temperatures $\left(>500{ }^{\circ} \mathrm{C}\right)$, alkalis have been proposed as catalysts. Alkalis promote the water gas shift and methanation reactions leading to more hydrogen and methane production and a carbon monoxide lean gas. The studies on whether or not alkalis enhance the extent of gasification are contradictory [10,44]. Recovery of alkalis from the process may be a problem, because alkalis hardly dissolve in supercritical water. Antal et al. [40] reported that leading the effluent of their empty tube reactor over a fixed bed of activated carbon derived from coconut increased the extent of gasification from 0.7 to 1.0. Despite the successful use of this activated carbon as a catalyst on laboratory scale, it may not be the catalyst finally selected for the process. Two important reasons are: (i) the catalytic activity nor its decline is understood and, (ii) the rate of coal gasification is slow but certainly not zero leading to consumption of the catalyst.

\subsection{Experimental results of model components gasification in hot compressed water}

As mentioned before the reaction rate of the available metal catalyst is too low for large-scale production of gaseous energy carriers from biomass at $350^{\circ} \mathrm{C}$. Raising the temperature is a proven method to accelerate chemical reactions. By adding the ruthenium catalyst to the quartz capillaries, complete gasification of glucose in the concentration range of $1-17 \mathrm{wt} \%$ is observed at a temperature of $600{ }^{\circ} \mathrm{C}$ and above [10] whereas without catalyst $Y_{\mathrm{c}}$ is only 0.7 (see Fig. 5A). Fig. 7 shows the measured gas production

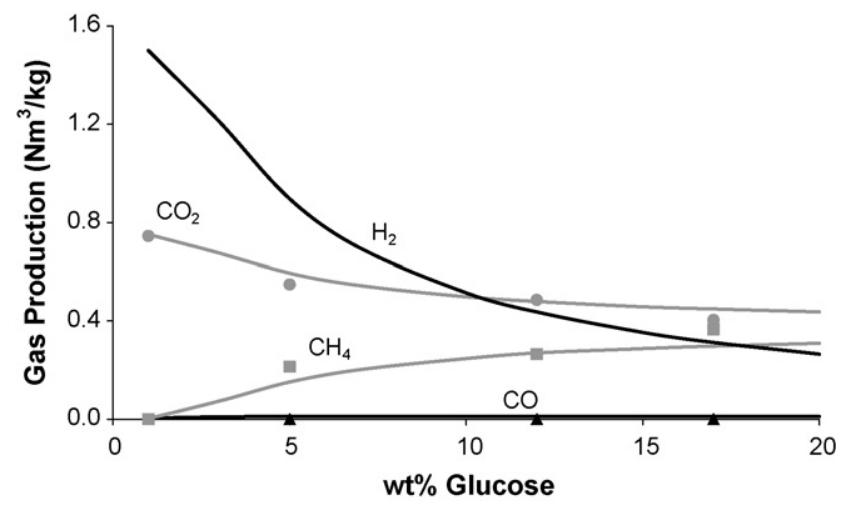

Fig. 7. Gas yields measured in the quartz capillaries vs. the concentration of glucose in the feedstock. $T=600{ }^{\circ} \mathrm{C} . P>250$ bar, $\mathrm{Ru}$ on $\mathrm{TiO}_{2}$ catalyst. Lines represent the chemical equilibrium. Measured hydrogen yields are not reported due to hydrogen calibration problems with the GC during this test series. in these tests and the thermodynamic gas production versus the concentration of glucose.

The measured gas productions are in good agreement with the gas productions dictated by thermodynamics. The difference with respect to the product between 350 and $600{ }^{\circ} \mathrm{C}$ is its composition: at low temperature the gas contains nearly only $\mathrm{CH}_{4}$ and $\mathrm{CO}_{2}$ (see ref. [8] and Fig. 5B) whereas at higher temperature it is a mixture of $\mathrm{CH}_{4}, \mathrm{H}_{2}$ and $\mathrm{CO}_{2}$. The efficiency of the catalyst particles in the capillary is difficult to define. This makes the experiments difficult to interpret and to compare with available results form literature on a quantitative rate basis. Therefore, catalytic experiments have been performed in our laboratory in a micro continuous reactor. Of this fixed catalytic bed the contacting pattern and LHSV are known allowing comparison with other work.

Experiments have been done with $10 \mathrm{wt} \%$ solutions of glycerol (A) and glucose (B) at $600{ }^{\circ} \mathrm{C}$ and 300 and 280 bar respectively (see Fig. 8).

The system is operated at a LHSV of $30 \mathrm{Nm}_{\text {fluid }}^{3} / \mathrm{h} / \mathrm{m}_{\text {cat }}^{3}$. The residence time at reaction conditions in our catalytic fixed bed is $10 \mathrm{~s}$, which is much lower compared to the 1000-2000 s used in the low temperature experiments [52]. However, that the density of the feedstock solution at $600{ }^{\circ} \mathrm{C}$ and 300 bar is ca. a factor 12 times lower than at $350^{\circ} \mathrm{C}$. This explains why the LHSV at $600{ }^{\circ} \mathrm{C}$ is only 12 times higher compared to LHSV applied by Elliott and coworkers at $350{ }^{\circ} \mathrm{C}\left(30 \mathrm{~h}^{-1}\right.$ vs. $\left.2.5 \mathrm{~h}^{-1}\right)$. By applying the ruthenium catalyst, complete gasification of the glycerol solution is achieved, whereas without catalyst $Y_{\mathrm{c}}=0.65$. For the glucose solution $Y_{\mathrm{c}}$ increased from 0.63 to 0.85 . In the capillaries, however, complete gasification of $10 \mathrm{wt} \%$ glucose has been reached with the
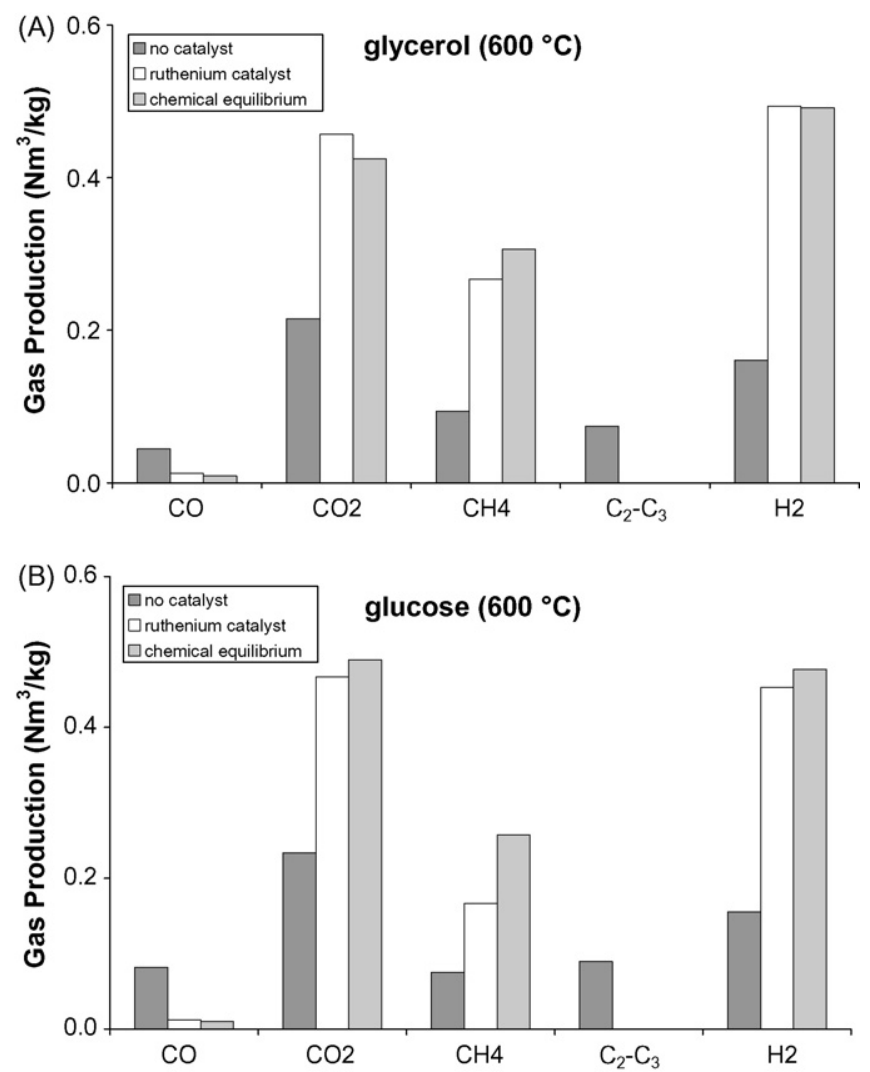

Fig. 8. Gas productions obtained in the micro continuous reactor with $10 \mathrm{wt} \%$ of glycerol (A) and glucose (B). Results with and without ruthenium catalyst are compared with chemical equilibrium. $T=600^{\circ} \mathrm{C}, P=300$ bar. LHSV $=30 \mathrm{~h}^{-1} \cdot \mathrm{C}_{2}-\mathrm{C}_{3}$ could not be detected in the tests with catalyst and according to equilibrium they are not present. 
ruthenium catalyst at $600{ }^{\circ} \mathrm{C}$ (see above). This difference is ascribed to the presence of produced carbonaceous deposits in the inert section before the catalytic section of the continuous reactor. When these deposits are not entrained with the main flow through the catalytic bed, their catalytic conversion is obviously not possible. When glycerol is not completely gasified, only liquids, which can be easily transported to the catalytic sites, are formed as by-products, never carbonaceous deposits [7]. The observation of carbonaceous solids (e.g. coke/char) outside the catalytic reactor defines a challenge for process design. In a real process there will always be carbonaceous deposits that (i) can be transported to the catalytic section for gasification, (ii) can be used to generate heat through combustion, or (iii) if ( $\mathrm{i}$ and ii) are not possible have to be purged. Possible solutions to handle deposits are discussed by Kersten et al. [55]. Fig. 8 shows that with the ruthenium catalyst the individual gas productions come very close to the yields of the thermodynamic productions. Hence, like at $350{ }^{\circ} \mathrm{C}$ the ruthenium on rutile tinania catalyst is also an equilibrium catalyst at $600{ }^{\circ} \mathrm{C}$. Shifting the gas composition to hydrogen or methane rich gas by relatively decelerating the formation of the unwanted product at the catalytic sites has not been investigated at a high temperature of $600{ }^{\circ} \mathrm{C}$. There are no data available on stability of the catalyst in the high temperature region, based on long duration testing.

Above primarily catalysis items are discussed. The challenges for reactor design are discussed by Kersten et al. [55] and can be summarized as follows: Reactor design should focus on: (i) optimizing the contact between reactants and catalysts preventing undesired homogeneous reactions leading to oil and char formation, (ii) creating the appropriate degree of back mixing to minimize the rate of higher order $(>1)$ poly condensation reactions while keeping the rate of the gasification reactions as high as possible, (iii) minimizing the required external heat demand of the reactor by utilizing the heat of the reactor effluent to heat the cold feed and/or internal heat generation, (iv) preventing blockages/ handling carbonaceous deposits and (v) purging the ashes and remaining carbonaceous deposits. Both catalysis and reactor design should proceed towards a process that can take in slurries of lignocelluloses. Due to the severe operating conditions, construction material selection is very important and is an item on its own.

\section{Conclusions}

The conclusions from this work are summarized below:

- At moderate temperatures $\left(<800{ }^{\circ} \mathrm{C}\right)$, a catalyst is always needed to produce a relatively clean syngas $\left(\mathrm{CO} / \mathrm{H}_{2}\right)$ or methane rich gas in high amounts. Without a catalyst a fuel gas $\left(\mathrm{CO}, \mathrm{CO}_{2}, \mathrm{CH}_{4}, \mathrm{H}_{2}\right.$, $\mathrm{C}_{2}-\mathrm{C}_{2}$ and tars) is produced with gasification of dry biomass. With wet biomass streams only a limited extent of gasification can be attained without catalysis.

- The application of a single vessel catalytic reactor configuration has up till now not been successful for biomass conversion processes. The catalysts suffer from (i) inefficient contact between the catalyst and the biomass (due to the texture of the biomass), (ii) poisoning by inorganics and deposition of char/ heavy tar from the biomass and (iii) harsh conditions in the single reactor (e.g. mechanical strength of catalyst needed to withstand fluidization). Single vessel systems do not have to be optimal; for instance two staged reactors operating at different temperatures provide the opportunity for heat integration.

- Gasification is a complex network of serial and parallel reactions. This can be used as an advantage when applying catalytic gasification by (i) smart arrangements of the processes and (ii) catalyst engineering.
- The staged overall conversion of biomass to syngas is an example of a smart arrangement of the processes. In the primary conversion to pyrolysis oil impurities, minerals and metals are concentrated in the char and due to the mild process conditions (ca. $500^{\circ} \mathrm{C}$ ) a highly oxygenated reactive oil is created. This oil can be effectively transported and if desired pressurized for the next conversion step. By reducing the cracking in the 'reevaporation' of the pyrolysis oil the formed gas/vapor mixture can be readily reformed to syngas in a staged reactor system consisting of a fluid bed evaporator/atomizer and catalytic reformer in series. In contrast, a cracked methane and secondary/ tertiary tar rich gas obtained at harsher evaporation conditions is more difficult to reform.

- A catalyst is required in gasification in hot compressed water to reach a high extent of gasification. At low temperature ( $300-$ $400{ }^{\circ} \mathrm{C}$ ) a catalyst is always required, at high temperature $\left(>600{ }^{\circ} \mathrm{C}\right.$ ) complete gasification can be achieved only without a catalyst if the feedstock is very diluted ( $\sim 1 \mathrm{wt} \%$ organics). With catalyst $\mathrm{CH}_{4}$ and $\mathrm{CO}_{2}$ are produced at low temperature, unless methanization and $\mathrm{C}-\mathrm{O}$ cleavage can be prevented at the catalytic sites [54]. Catalytic gasification of biomass in hot compressed water at high temperature produces a mixture of $\mathrm{CH}_{4}, \mathrm{H}_{2}$ and $\mathrm{CO}_{2}$. The advantage of operating at a higher temperature is a significant increase in reaction rate. Catalysts have been developed and tested in long duration tests for the low temperature region, for high temperatures no catalyst stability data are available.

- For both dry and wet gasification, catalyst stability towards sintering, poisoning and resistance to fouling, leaching and attrition should be important research items next to investigating catalytic activity.

\section{Acknowledgements}

Catalytic gasification of pyrolysis oil been performed in the framework of an EU project (Bio-electricity, ENK5 CT-2002-00634) and a NWO-ACTS project (Sustainable hydrogen, 053.61.007). The authors would like to thank Johnson Matthey for supplying the $\mathrm{Ni}$ on alumina based commercial reforming catalysts, BTG for facilitating the research.

For the gasification in hot compressed water, the Dutch government via NWO, Shell, The European Commission and NEDO are gratefully acknowledged for their financial support and Pacific Northwest National Laboratory is acknowledged for providing the $\mathrm{Ru}$ on $\mathrm{TiO}_{2}$ catalyst.

\section{References}

[1] S.R.A. Kersten, W.P.M. van Swaaij, L. Lefferts, K. Seshan, Catalysis for Renewables, Wiley-VCH, Weinheim, 2007, p. 119

[2] P.R. Ramage, R. Agrawal, The Hydrogen Economy: Opportunities, Costs, Barriers and R\&D Needs, National Academies Press, Washington, DC, 2004.

[3] M.F. Bleeker, S.R.A. Kersten, H.J. Veringa, Catal. Today 127 (2007) 278.

[4] G. van Rossum, S.R.A. Kersten, W.P.M. van Swaaij, Ind. Eng. Chem. Res. 46 (2007) 3959.

[5] B. Potic, S.R.A. Kersten, W. Prins, W.P.M. van Swaaij, Ind. Eng. Chem. Res. 43 (2004) 4580.

[6] D. Knežević, D. Schmiedl, D. Meier, S.R.A. Kersten, W.P.M. van Swaaij, Ind. Eng. Chem. Res. 46 (2007) 1810.

[7] B. Potic, Gasification of biomass in supercritical water, Master Thesis, University of Twente, 2006.

[8] D.C. Elliott, G.G. Neuenschwander, T.R. Hart, R.S. Butner, A.H. Zacher, M.H. Engelhard, J.S. Young, D.E. McCready, Ind. Eng. Chem. Res. 43 (2004) 1999.

[9] M.H. Waldner, F. Vogel, Ind. Eng. Chem. Res. 44 (2005) 4543.

[10] S.R.A. Kersten, B. Potic, W. Prins, W.P.M. van Swaaij, Ind. Eng. Chem. Res. 45 (2006) 4169.

[11] B.G. Kyle, Chemical and Process Thermodynamics, Prentice Hall PTR, Englewood Cliffs, NJ, 1999.

[12] G. Soave, M. Barolo, A. Bertucco, Fluid Phase Equilib. 91 (1993) 87.

[13] A. Bertucco, M. Barolo, G. Soave, Ind. Eng. Chem. Res. 34 (1995) 3159. 
[14] G. Soave, Chem. Eng. Sci. 27 (1972) 1197.

[15] National Institute of Standards and Technology, Gaithersburg, MD.

[16] H.A. Marshall, F.C.R.M. Smits, in: Proceedings of 9th International Conference on Coal Gasification Liquefaction and Conversion to Electricity, Pittsburgh, (1981), p. 357.

[17] C. Higman, M. van der Burgt, Gasification, Elesevier Science, New York, 2003.

[18] D. Sutton, B. Kelleher, J.R.H. Ross, Fuel Processing Technology 73 (2001) 155.

[19] A.A.C.M. Beenackers, W.P.M. van Swaaij, in: Proceedings of 1st European Workshop On Thermochemical Processing of Biomass, Butterworths, 1984

[20] K. Maniatis, Progress in biomass gasification: an overview, in: A.V. Bridgwater (Ed.), Progress in Thermochemical Biomass Conversion, vol. 1, Blackwell Science Ltd., UK, 2001, p. 1.

[21] E. Dinjus, E. Henrich, M. Schingnitz, in: Proceedings of 14th European Biomass Conference, Paris, October 17-21, (2005), p. 1663.

[22] J. Corella, A. Orío, M.P. Aznar, Ind. Eng. Chem. Res. 37 (1998) 4617

[23] A. Olivares, M.P. Aznar, M.A. Caballero, J. Gil, E. Francés, J. Corella, Ind. Eng. Chem. Res. 36 (1997) 5220

[24] J. Corella, M.P. Aznar, J. Gil, M.A. Caballero, Energy Fuels 13 (1999) 1122.

[25] M.A. Caballero, J. Corella, M.P. Aznar, J. Gil, Ind. Eng. Chem. Res. 39 (2000) 1143.

[26] S. Rapagnà, N. Jand, A. Kiennemann, P.U. Foscolo, Biomass Bioenergy 19 (2000) 187.

[27] J. Corella, M.T. Toledo, R. Padilla, Energy Fuels 18 (2004) 713.

[28] C. Courson, L. Udron, D. Świerczyński, C. Petit, A. Kiennemann, Catal. Today 76 (2002) 75.

[29] P. Simell, E. Kurkela, P. Ståhlberg, J. Hepola, Catal. Today 27 (1996) 55.

[30] D. Wang, S. Czernik, D. Montańe, M. Mann, E. Chornet, Ind. Eng. Chem. Res. 36 (1997) 1507.

[31] S. Czernik, R. French, C. Feik, E. Chornet, Ind. Eng. Chem. Res. 41 (2002) 4209

[32] G. van Rossum, S.R.A. Kersten, W.P.M. van Swaaij, in: Proceedings of 14th European Biomass Conference, Paris, 17-21 Oct, (2005), p. 592.

[33] M.P. Aznar, J. Corella, J. Delgado, J. Lahoz, Ind. Eng. Chem. Res. 32 (1993) 1.

[34] K.A. Magrini-Bair, S. Czernik, R. French, Y.O. Parent, E. Chornet, D.C. Dayton, C. Feik, R. Bain, Appl. Catal. A 318 (2007) 199.

[35] J.R. Rostrup-Nielsen, J. Sehested, J.K. Nørskov, Adv. Catal. 47 (2002) 66.
[36] C. Rioche, S. Kulkarni, F.C. Meunier, J.P. Breen, R. Burch, Appl. Catal. B 61 (2005) 130.

[37] K. Takanabe, K. Aika, K. Inazu, T. Baba, K. Seshan, L. Lefferts, J. Catal. 243 (2006) 263.

[38] A.C. Basagiannis, X.E. Verykios, Catal. Today 127 (2007) 256

[39] Y. Matsumura, T. Minowa, B. Potic, S.R.A. Kersten, W. Prins, W.P.M. van Swaaij, L. van de Beld, D.C. Elliot, G.G. Neuenschwander, A. Kruze, M.J. Antal, Biomass Bioenergy 29 (2005) 269.

[40] M.J. Antal, S.G. Allen, D. Schulman, X. Xu, R.J. Divilio, Ind. Eng. Chem. Res. 39 (2000) 4040.

[41] X. Xu, Y. Matsumura, J. Stenberg, M.J. Antal, Ind. Eng. Chem. Res. 35 (1996) 2522.

[42] D. Yu, M. Aihara, M.J. Antal, Energy Fuels 7 (1993) 574.

[43] D. Knežević, M. Rep, S.R.A. Kersten, W. Prins, W.P.M. van Swaaij, Hydrothermal liquefaction and pyrolysis: a visualization study, in: A.V. Bridgwater, D.G.B Boocock (Eds.), Science in Thermal and Chemical Biomass Conversion, vol. 2, CPL Press, UK, 2006, p. 1082.

[44] A. Sinağ, A. Kruse, V. Schwarzkopf, Ind. Eng. Chem. Res. 42 (2003) 3516.

[45] A. Kruse, E. Dinjus, J. Supercrit. Fluids 41 (2007) 361.

[46] R.D. Cortright, R.R. Davda, J.A. Dumesic, Nature 418 (2002) 964.

[47] S. Dumitriu (Ed.), Polysaccharides, second ed., Marcel Dekker, New York, 2005 p. 893.

[48] T. Minowa, Z. Fang, T. Ogi, G. Várhegyi, J. Chem. Eng. Jpn. 31 (1998) 131

[49] B.M. Kabyemela, T. Adschiri, R.M. Malaluan, K. Arai, Ind. Eng. Chem. Res. 36 (1997) 1552.

[50] L.J. Sealock, D.C. Elliott, E.G. Baker, R.S. Butner, Ind. Eng. Chem. Res. 32 (1993) 1535.

51] D.C. Elliott, L.J. Sealock, E.G. Baker, Ind. Eng. Chem. Res. 33 (1994) 558.

[52] D.C. Elliott, T.R. Hart, G.G. Neuenschwander, Ind. Eng. Chem. Res. 45 (2006) 3776.

[53] D. Knežević, S.R.A. Kersten, W.P.M. van Swaaij, Ind. Eng. Chem. Res., submitted for publication.

[54] G.W. Huber, J.W. Shabaker, J.A. Dumesic, Science 300 (2003) 2075.

[55] S.R.A. Kersten, W. Prins, W.P.M. van Swaaij, in: Proceedings of Second World Conference and Technology Exhibition on Biomass for Energy Industry and Climate Protection, Rome, May 10-14, (2004), p. 777. 